\title{
The Relationship between Productivity and Inflation: An Empirical Analysis of the Brazilian Economy
}

\author{
Denise Piper' ${ }^{1}$, Fernando Ferrari-Filho',3, Marcos Tadeu Lélis ${ }^{3,4}$ \\ ${ }^{1}$ Economics at Universidade Franciscana, Santa Maria, Brazil \\ ${ }^{2}$ Economics at Unifersidade Federal do Rio Grande do Sul, Porto Alegre, Brazil \\ ${ }^{3}$ Researcher at CNPq, Brasília, Brazil \\ ${ }^{4}$ Economics at Unisinos, São Leopoldo, Brazil \\ Email: ferrari@ufrgs.br
}

How to cite this paper: Piper, D., Ferrari-Filho, F. and Lélis, M.T. (2020). The Relationship between Productivity and Inflation: An Empirical Analysis of the Brazilian Economy. Theoretical Economics Letters, 10, 563-578.

https://doi.org/10.4236/tel.2020.103036

Received: May 8, 2020

Accepted: June 6, 2020

Published: June 9, 2020

Copyright $\odot 2020$ by author(s) and Scientific Research Publishing Inc. This work is licensed under the Creative Commons Attribution International License (CC BY 4.0).

http://creativecommons.org/licenses/by/4.0/

\begin{abstract}
The article presents an empirical test of the hypothesis that productivity expansions are the answer to the inflation problems experienced by the Brazilian economy. The study obtained evidence from the estimation of a Structural Autoregressive Vector (SVAR) model for the period after December 2009, which confirmed the existence of an inverse relationship between inflation and productivity in Brazil's manufacturing industry. However, this relationship is inelastic; that is, Brazilian entrepreneurs tend to convert productivity gains into mark-up instead of passing them on to prices. Thus, productivity increases yield smaller inflation control effects than expected.
\end{abstract}

\section{Keywords}

Economic Development, Inflation Targeting Regime, Non-Monetary

Controls, Productivity

\section{Introduction}

In June 1999, Brazil's monetary authorities introduced the inflation-targeting regime (ITR). The ITR replaced the Real Plan stabilization program and was based on an exchange-rate anchor to keep inflation under control while also serving as a monetary anchor to balance the current account of the balance of payments (e.g., Ferrari Filho \& Paula, 2003). From then on, SELIC-the basic interest rate set by Banco Central do Brasil (BCB)—a officially became the main instrument for controlling inflation in Brazil's economy. 
However, a number of economists (e.g., Arestis, Ferrari Filho, \& Paula, 2011; Modenesi \& Araujo, 2013) have come to question the relation between the SELIC rate and inflation, problematizing the degree to which interest rate increases have been successful in fostering price stability in Brazil. A simple examination of mean annual SELIC and inflation rates from 1999 to 2018 justifies these questions: during that 1999-2018 period, although the SELIC rate was kept high (at a mean of $14.4 \%$ p.a.), inflation in Brazil also remained high for an ITR, as the Extended Consumer Price Index (IPCA) averaged 6.6\% p.a. Also, in the 20 years during which the ITR has been in place in Brazil, the upper limit set for inflation was breached within five years, and during only four out of the 20 years did inflation remain below the pre-established target.

There is no shortage of explanations for the peculiarities of inflation in Brazil under the ITR (e.g., Araujo \& Arestis, 2019). It is argued in this article that inflation in Brazil is not primarily a demand phenomenon, as the ITR presupposes, but instead is determined mainly by: 1) inflation inertia; 2) administered price-adjustment policies; 3) international dollar price and exchange rate dynamics; 4) rising wage trends; and 5) low productivity in manufacturing sectors. In recent years, in the wake of the idea that low productivity in the manufacturing sectors affects the inflation rate, numerous studies (for instance, Silva, Feijó, \& Modenesi, 2018) have risen to prominence suggesting that a single concrete and definitive solution to the problems of inflation facing Brazil's economy would be to stimulate productivity across the widest possible range of productive sectors.

In the meantime, Braga (2011: pp. 121, 129, translated by the authors) remarked that "policies that promote economic development can have significant beneficial impacts on the process of maintaining prices stable, even in a context of rapid growth," and that, in the conjuncture of Brazil's cost-push inflation, "aggregate productivity gains have sought to offset growth in average wages." For their part, Gentil and Araujo (2015) argued that the inflation observed recently in the Brazilian economy has shown itself to be a phenomenon influenced primarily by the existence of distributive conflicts, which means that accommodating the distributive conflict depends on obtaining productivity gains by focusing on productive structure, innovation and investment. In their words:

Low growth in productivity in a context of rising real wages has led to discomfort in accommodating the distributive conflict latent in Brazilian society, resulting in inflationary pressures that, as a rule, have been combated by means of restrictive macroeconomic policies, subjecting Brazil's economy to a stop-go type growth trajectory (Gentil \& Araujo, 2015: p. 55, translated by the authors).

In any case, however extensively this idea may have been introduced and discussed in analyses of inflation in Brazil in the post-ITR period, there is little empirical evidence to support its validity within the existing economic literature. Accordingly, and seeking to fill that gap, this article empirically tests the nature 
of the relationship between inflation and productivity in Brazil. The article comprises four sections in addition to this Introduction. The next section briefly explains the reasons motivating the choice of model to be estimated, and describes the information difficulties involved in that estimation. Section 3 presents the methodology guiding the empirical part of the study. Section 4 examines the results obtained from the estimation processes employed. The final section lays out the authors' conclusions.

\section{Theoretical Definition of the Model and Information Constraints}

Generally, the studies that recommend increasing productivity as a means of ensuring price stability ultimately base their propositions on the impacts upon production costs yielded by productivity. For the purposes of this article, it was decided to base the empirical analysis on a model whose functional specification is inspired by Câmara and Feijó (2017), whose model employed the variation in the Producer Price Index (PPI) as a measure of inflation-in place of the more commonly used IPCA. This is because PPI more precisely reflects the dynamics of production costs, given that it is limited to the realm of production-whereas IPCA is susceptible to contamination by elements connected with the circulation of goods.

However, as the core purpose of Câmara and Feijó (2017) diverges from the basic question guiding this study, important alterations have been made here to the model previously proposed by those authors. In that regard, while the model in Câmara and Feijó (2017) uses nominal wage per unit of output as its measure of wage cost, this study uses the concept of nominal wage paid per worker. This enables the model to isolate the effect of productivity, which is a variable those authors did not explicitly consider.

The decision to use PPI in the econometric analysis does, however, entail certain operational difficulties that culminate in constraints upon the study time period and sectors included. It is only recently that Brazil's official statistics bureau-Instituto Brasileiro de Geografia e Estatística (IBGE)—has published historical series for PPI (IBGE, 2019), so that, in order to maximize the sample size, it was necessary to employ the PPI series for the manufacturing industry, which began in December 2009. The other variants of PPI-for the extractive industry and for industry in general-did not begin until December 2013. Furthermore, there is no aggregate measure for the indicator in question that covers all sectors of domestic economic activity.

Another technical difficulty posed by estimation of the model was that, in 2002 , the IBGE interrupted its calculation of the series assessing productivity in the manufacturing industry. Since then, all empirical studies on the subject have been estimating the manufacturing industry productivity variable by dividing the series for physical production and hours paid in industry overall. Thus, it has been possible to measure productivity in the manufacturing industry, despite the fact that this requires using the same denominator as is used in the ratio de- 
scribed above. In this study, the series of hours worked in production in the manufacturing industry was based on the data provided by the Confederação Nacional da Indústria (CNI).

Although the scarcity of available statistics ultimately restricted the scope of the sample-which was initially intended to comprise all sectors of economic activity as well as the complete period during which the ITR was in place in Brazil-the results presented here are nevertheless significant. In addition, it is the manufacturing industry (the most dynamic sector of economic activity) that is being studied at a time when the ITR was fully established in Brazil, meaning that the results are both important and thought-provoking.

\section{Methodological Considerations}

\subsection{Estimation Method}

The estimates presented here are derived from the application of the Autoregressive Vector (VAR) and Structural Autoregressive Vector (SVAR) methodologies, which, as explained by Enders (2015), draw on multiple-equation time series, within which context all variables are treated symmetrically as endogenous.

The system of equations below illustrates the structure of the VAR model in its most simplistic version (i.e., the first-order bivariate case):

$$
y_{t}=b_{10}-b_{12} x_{t}+\gamma_{11} y_{t-1}+\gamma_{12} x_{t-1}+\varepsilon_{y t}
$$

and

$$
x_{t}=b_{20}-b_{21} y_{t}+\gamma_{21} y_{t-1}+\gamma_{22} x_{t-1}+\varepsilon_{x t} .
$$

In Equations (1) and (2), the assumption is that the variables $y$ and $x$ are both stationary and that $\varepsilon_{y t}$ and $\varepsilon_{x t}$ consist in white-noise-type error terms.

These equations constitute a first-order VAR model, as the longest time lag included on the right-hand side of the equations is only one period. The VAR model, in accordance with the equations, cannot be estimated directly by the Ordinary Least Squares technique, because there is a problem of endogeneity-given that $x$ has a contemporary effect on $y$ and vice versa. Accordingly, the estimation process must transform this primitive system into what is termed a "standard-form VAR model" performed by the algebraic procedures described below.

Rewriting Equations (1) and (2) gives:

$$
y_{t}+b_{12} x_{t}=b_{10}+\gamma_{11} y_{t-1}+\gamma_{12} x_{t-1}+\varepsilon_{y t}
$$

and

$$
b_{21} y_{t}+x_{t}=b_{20}+\gamma_{21} y_{t-1}+\gamma_{22} x_{t-1}+\varepsilon_{x t} .
$$

These can be restructured into the matrix system:

$$
\left[\begin{array}{cc}
1 & b_{12} \\
b_{21} & 1
\end{array}\right]\left[\begin{array}{l}
y_{t} \\
x_{t}
\end{array}\right]=\left[\begin{array}{l}
b_{10} \\
b_{20}
\end{array}\right]+\left[\begin{array}{ll}
\gamma_{11} & \gamma_{12} \\
\gamma_{21} & \gamma_{22}
\end{array}\right]\left[\begin{array}{l}
y_{t-1} \\
x_{t-1}
\end{array}\right]+\left[\begin{array}{l}
\varepsilon_{y t} \\
\varepsilon_{x t}
\end{array}\right] .
$$


The matrix system can be rewritten as:

$$
\begin{gathered}
\boldsymbol{B z}_{t}=\Gamma_{0}+\Gamma_{1} \mathbf{z}_{t-1}+\boldsymbol{\varepsilon}_{t} \\
\text { where: } \quad \boldsymbol{B}=\left[\begin{array}{cc}
1 & b_{12} \\
b_{21} & 1
\end{array}\right], \quad \mathbf{z}_{t}=\left[\begin{array}{l}
y_{t} \\
x_{t}
\end{array}\right], \quad \Gamma_{0}=\left[\begin{array}{l}
b_{10} \\
b_{20}
\end{array}\right], \quad \Gamma_{1}=\left[\begin{array}{ll}
\gamma_{11} & \gamma_{12} \\
\gamma_{21} & \gamma_{22}
\end{array}\right] \text { and } \\
\boldsymbol{\varepsilon}_{t}=\left[\begin{array}{c}
\varepsilon_{y t} \\
\varepsilon_{x t}
\end{array}\right] \\
\text { Pre-multiplying (6) by } \boldsymbol{B}^{-1} \text { gives: } \\
\boldsymbol{B}^{-1} \mathbf{B z}_{t}=\boldsymbol{B}^{-1} \Gamma_{0}+\boldsymbol{B}^{-1} \Gamma_{1} \mathbf{z}_{t-1}+\boldsymbol{B}^{-1} \boldsymbol{\varepsilon}_{t}
\end{gathered}
$$

and

$$
\mathbf{z}_{t}=A_{0}+A_{1} \mathbf{z}_{t-1}+e_{t} .
$$

In the previous Equation (8), which relates to the standard-form VAR model, the values of $\boldsymbol{A}_{0}, \boldsymbol{A}_{1}$, and $\boldsymbol{e}_{t}$ are the following: $\boldsymbol{A}_{0}=\boldsymbol{B}^{-1} \Gamma_{0}, \boldsymbol{A}_{1}=\boldsymbol{B}^{-1} \Gamma_{1}$ and $\boldsymbol{e}_{t}=\boldsymbol{B}^{-1} \varepsilon_{t}$.

Lastly, (8) can be rewritten as:

$$
y_{t}=\alpha_{10}+\alpha_{11} y_{t-1}+\alpha_{12} x_{t-1}+e_{1 t}
$$

and

$$
x_{t}=\alpha_{20}+\alpha_{21} y_{t-1}+\alpha_{22} x_{t-1}+e_{2 t} .
$$

The coefficients for the primitive model are identified from the standard-form model by way of a resource known as the Cholesky decomposition, following Sims (1980), which is processed by decomposing the residuals into a triangular matrix, thus giving rise to a recursive system. In terms of the matrix system (5), the Cholesky decomposition can be illustrated on the basis that $b_{21}=0$, which means assuming that $y_{t}$ exerts no contemporary influence on $x_{t}$, thus conferring on $y_{t}$ a greater degree of endogeneity in the system in relation to $x_{t}$. In other words, the restriction that $b_{21}=0$ entails the hypothesis that $\varepsilon_{y t}$ and $\varepsilon_{x t}$ have contemporary impact on $y_{t}$, but only $\varepsilon_{x t}$ has contemporary impact on $x_{t}$. Enders (2015: p. 294) argues that:

In an $n$-variable VAR, $B$ is an $n \times n$ matrix since there are $n$ regression residuals and $n$ structural shocks. [...] exact identification requires that $\left(n^{2}-n\right) / 2$ restrictions be placed on the relationship between the regression residuals and the structural innovations. Since the Cholesky decomposition is triangular, it forces exactly $\left(n^{2}-n\right) / 2$ values of the $B$ matrix to equal zero.

Important diagnostic instruments derived from the VAR methodology include impulse-response functions and variance decomposition analysis. Impulse-response functions make it to possible to assess, both qualitatively and quantitatively, how the variables included in the model behave in response to shocks-specifically, in the system described here, how $y_{t}$ and $x_{t}$ react to the dynamics of $\varepsilon_{y t}$ and $\varepsilon_{x t}$. Variance decomposition analysis, meanwhile, clari- 
fies what proportion of the movements of a given variable are attributable to the shocks on that particular variable as well as the proportion due to shocks on the other variables.

VAR models have come in for strong criticism over time because of their essentially theory-free nature, which will not admit the incorporation of knowledge from economic theory. This has led to the development of SVAR models, with which economic theory can be used as a basis for imposing restrictions on the model and thus producing results that are not ad hoc. Accordingly, other decompositions are performed in parallel with the Cholesky decomposition, as in Sims (1980), and in that context, it is possible to impose error constraints so as to allow for the identification of structural shocks in a manner consistent with the theoretical underpinning of the model in question. Bueno (2015: p. 226, translated by the authors) states that:

In such forms, economic arguments are followed more strictly, to the point that constraints are applied that go as far as to over-identify the model if the number of constraints is greater than the number of coefficients estimated in the reduced form. That is, while the methodology of Sims (1980) used the economy to specify an order of variables, it is possible to seek economic constraints more comprehensively. That is, economic theory is used to specify constraints on the A matrix completely.

The Blanchard and Quah (1989) decomposition is also performed, which allows even the variables' long-term dynamics to be analyzed. Lütkepohl (2005) explained that this decomposition is founded on the principle that it is unnecessary to impose constraints directly on the matrices in order to identify structural shocks. In order to exemplify the Blanchard-Quah decomposition with regard to our bivariate model, let us suppose that the sequence to be decomposed is of variable $y_{t}$, assuming $\mathrm{I}(1)$, as regards its transitory and permanent components, and that $x_{t}$ is stationary. Disregarding the intercepts, in the Blanchard \& Quah (1989) decomposition the sequences $\left\{y_{t}\right\}$ and $\left\{x_{t}\right\}$ can be represented as:

$$
\Delta y_{t}=\sum_{k=0}^{\infty} c_{11}(k) \varepsilon_{1 t-k}+\sum_{k=0}^{\infty} c_{12}(k) \varepsilon_{2 t-k}
$$

and

$$
x_{t}=\sum_{k=0}^{\infty} c_{21}(k) \varepsilon_{1 t-k}+\sum_{k=0}^{\infty} c_{22}(k) \varepsilon_{2 t-k} .
$$

In terms of matrix notation:

$$
\left[\begin{array}{c}
\Delta y_{t} \\
x_{t}
\end{array}\right]=\left[\begin{array}{cc}
C_{11}(L) & C_{12}(L) \\
C_{21}(L) & C_{22}(L)
\end{array}\right]\left[\begin{array}{c}
\varepsilon_{1 t} \\
\varepsilon_{2 t}
\end{array}\right],
$$

where $\varepsilon_{1 t}$ and $\varepsilon_{2 t}$ are independent white-noise shocks, and the components $C_{i j}(L)$ of the $C$ matrix are L-degree polynomials whose individual coefficients are denoted as $C_{i j}(k)$.

Use of the Blanchard-Quah decomposition requires that at least one of the variables involved in the estimation process not be stationary, given that stationary 
variables have no permanent component-which is essential to conduct the long-term analysis. However, the technique is employed by introducing the variables into the model in their stationary forms. Note that the Blanchard-Quah procedure does not associate shocks on $\left\{\varepsilon_{1 t}\right\}$ and $\left\{\varepsilon_{2 t}\right\}$ directly with the sequences $\left\{y_{t}\right\}$ and $\left\{x_{t}\right\}$; on the contrary, the sequences $\left\{y_{t}\right\}$ and $\left\{x_{t}\right\}$ are taken to be endogenous variables, and the sequences $\left\{\varepsilon_{1 t}\right\}$ and $\left\{\varepsilon_{2 t}\right\}$ are what could be termed exogenous variables.

\subsection{Specification of the Model}

The vector of variables, $\mathbf{z}$, for the VAR and SVAR systems estimated, is composed as follows:

$$
\mathbf{z}=\left[\begin{array}{c}
A \\
\epsilon \\
i \\
u \\
w \\
P_{p}
\end{array}\right],
$$

where: $A$ is the productivity of labor in the manufacturing industry; $\epsilon$ is the nominal exchange rate; $i$ is the basic market interest rate; $u=$ utilization of installed capacity in the manufacturing industry; $w$ is the average nominal wage paid in the manufacturing industry; and $P_{p}$ is the producer price index for the manufacturing industry.

\subsection{Description of the Variables}

In order to perform the estimates, monthly data were used for the period from December 2009 to July 2017, totaling 92 observations. As mentioned above, the time range and industrial sector of reference for the analysis were chosen in view of data availability. The variables involved in the estimation process were specified as follows:

1) $p t d=$ index for labor productivity in the manufacturing industry. Calculated as the ratio of the portion of the monthly industrial index (PIM) relating to the manufacturing industry (Source: IBGE, 2019) to the index for hours worked in production in the manufacturing industry (Source: CNI, 2019);

2) $\mathrm{cmb}$ = index for nominal exchange rate. Commercial exchange, end of period, mean of buy and sell (Source: BCB, 2019);

3) $j u r=$ index for nominal market interest rate. SELIC rate, \% p.m. (Source: $\mathrm{BCB}, 2019)$;

4) $u c i=$ index for utilization of installed capacity in the manufacturing industry. Mean percentage (Source: CNI, 2019);

5) $s l r=$ index for mean nominal wage paid in the manufacturing industry. Calculated as the ratio of the index for the manufacturing industry wage bill (Source: CNI, 2019) to the index for employees in the manufacturing industry (Source: CNI, 2019); 
6) $i p p=$ IPP for the manufacturing industry (Source: IBGE, 2019).

All the indices used are tied to the same base; that is, 2012 average $=100$. The variables were de-seasonalized by the Census X-13 method. In the estimation process, they were used in logarithm form.

\section{Analysis of the Results}

Table 1 and Table 2 show the results of the unit root tests performed on the variables included in the model to be estimated. In view of the divergences found among the tests performed, it was concluded that all the variables could be considered to be I(1). That assertion includes the interest rates-although the Augmented Dickey-Fuller and Zivot-Andrews tests do leave room for ambiguities-because the other tests confirmed the stationarity hypothesis when that variable was considered in first difference. As it was found that all the variables had to be included in the model in their first-difference versions, it can be seen that, given that the variables were expressed in logarithmic form, the coefficients for the estimates executed will refer to elasticities.

To select the order of SVAR model, an examination of the statistics condensed in Table 3 reveals that, while the Akaike information criterion (AIC) suggests using 3 lags, the Schwartz information criterion (SIC) indicates a second-order model. However, it is only possible to obtain a model that is homoscedastic and non-auto-correlated by including at least 4 lags in the model. Specification of a second-order SVAR model would entail the existence of auto-correlation, as well as that of heteroscedasticity in the equation underlying the variable duci. Thus, a third-order SVAR model would be subject to the presence of heteroscedasticity in the equation for the variable $d c m b$.

Accordingly, it was decided to estimate a fourth-order SVAR model, which, in addition to the good results mentioned above as regards tests of heteroscedasticity and auto-correlation, also offered excellent normality statistics, as shown in Table 4. Only one equation (for the variable $d c \mathrm{cmb}$ ) pointed toward problems of normality (a result that can be considered quite satisfactory, in comparison with what is commonly found when working with estimation procedures), and the model as a whole proved normal. Also, with the inclusion of 4 lags, the model proved stable (as seen in Figure 1).

As a first exercise, with a view to identifying the short-term behavior of the variables involved in the estimation process, the Cholesky decomposition was performed for the proposed model. The results are summarized in Table 5. When the Cholesky decomposition was analyzed, with the assistance of the tables, for the equivalent impulse-response functions, only the variables relating to exchange rate and PPI itself were found to have a statistically significant influence on inflation. Those results were quite consistent with the existing literature (Aizenman, Hutchison, \& Noy, 2011; Fonseca, Peres, \& Araújo, 2016), which in fact shows exchange to be the main variable affecting inflation in the short run, and also highlights the importance of inflation inertia in recent times. 


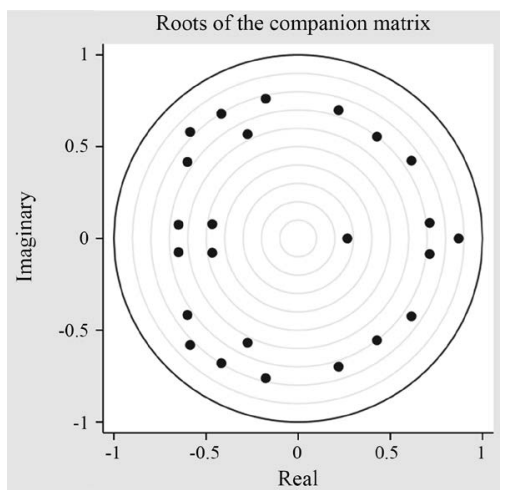

Figure 1. Test of the model: stability testing. Source: Results from the estimation process.

Table 1. Unit Roots Test, variables in levels.

\begin{tabular}{|c|c|c|c|c|c|c|c|}
\hline & TEST & Ptd & $\mathrm{cmb}$ & jur & uci & slr & ipp \\
\hline \multirow{2}{*}{$\mathrm{ADF}$} & t-statistic & $-2.711528^{\star}$ & -0.666589 & -2.321665 & $-2.803488^{\star}$ & $-3.631234^{\star}$ & $-2.650261^{\star}$ \\
\hline & p-value & 0.2347 & 0.8490 & 0.1676 & 0.2000 & 0.0326 & 0.2597 \\
\hline \multirow{4}{*}{ KPSS } & LM statistic & $0.174206^{*}$ & $0.114257^{*}$ & $0.148539^{*}$ & $0.271630^{*}$ & $0.218900^{*}$ & $0.086862^{\star}$ \\
\hline & Critical Value $1 \%$ & 0.216000 & 0.216000 & 0.216000 & 0.216000 & 0.216000 & 0.216000 \\
\hline & Critical Value 5\% & 0.146000 & 0.146000 & 0.146000 & 0.146000 & 0.146000 & 0.146000 \\
\hline & Critical Value $10 \%$ & 0.119000 & 0.119000 & 0.119000 & 0.119000 & 0.119000 & 0.119000 \\
\hline \multirow{2}{*}{ ADF (Break) } & t-statistic & -2.586509 & -2.553750 & -3.709575 & -2.894235 & -1.884412 & -2.591340 \\
\hline & p-value & 0.8737 & 0.8860 & 0.2781 & 0.7417 & 0.9881 & 0.8719 \\
\hline \multirow{4}{*}{$\mathrm{ZA}$} & t-statistic & -3.895 & -3.069 & -2.496 & -5.055 & -3.527 & -2.614 \\
\hline & Critical Value $1 \%$ & -5.34 & -5.34 & -5.34 & -5.34 & -5.34 & -5.34 \\
\hline & Critical Value 5\% & -4.80 & -4.80 & -4.80 & -4.80 & -4.80 & -4.80 \\
\hline & Critical Value $10 \%$ & -4.58 & -4.58 & -4.58 & -4.58 & -4.58 & -4.58 \\
\hline
\end{tabular}

Note: ADF = Augmented Dickey-Fuller; KPSS = Kwiatkowski-Phillips-Schmidt-Shin; ADF Break = Augmented Dickey-Fuller with structural break; ZA = Zivot-Andrews; and * Test equation with time trend term. Source: Results of the estimation process. Produced by the authors.

Table 2. Unit Roots Test, variables in first difference.

\begin{tabular}{|c|c|c|c|c|c|c|c|}
\hline \multicolumn{2}{|r|}{ TEST } & \multirow{2}{*}{$\begin{array}{c}\text { Dptd } \\
-13.96488^{*}\end{array}$} & \multirow{2}{*}{$\begin{array}{c}\text { Dcmb } \\
-9.760973\end{array}$} & \multirow{2}{*}{$\begin{array}{c}\text { djur } \\
-1.991412\end{array}$} & \multirow{2}{*}{$\begin{array}{c}\text { duci } \\
-13.32437\end{array}$} & \multirow{2}{*}{$\begin{array}{c}\text { dslr } \\
-12.76937\end{array}$} & \multirow{2}{*}{$\begin{array}{c}\text { dipp } \\
-6.542762\end{array}$} \\
\hline זמת & t-statistic & & & & & & \\
\hline $\mathrm{ADF}$ & $\mathrm{p}$-value & 0.0000 & 0.0000 & 0.2901 & 0.0001 & 0.0001 & 0.0000 \\
\hline \multirow{6}{*}{ ADF (Break) } & LM statistic & 0.223430 & 0.115096 & 0.139291 & 0.058259 & 0.124130 & 0.173177 \\
\hline & Critical Value $1 \%$ & 0.739000 & 0.739000 & 0.739000 & 0.739000 & 0.739000 & 0.739000 \\
\hline & Critical Value 5\% & 0.463000 & 0.463000 & 0.463000 & 0.463000 & 0.463000 & 0.463000 \\
\hline & Critical Value $10 \%$ & 0.347000 & 0.347000 & 0.347000 & 0.347000 & 0.347000 & 0.347000 \\
\hline & $\mathrm{t}$-statistic & -14.61660 & -10.84901 & -14.32303 & -13.66376 & -13.45417 & -7.425025 \\
\hline & $\mathrm{p}$-value & $<0.01$ & $<0.01$ & $<0.01$ & $<0.01$ & $<0.01$ & $<0.01$ \\
\hline \multirow{4}{*}{$\mathrm{ZA}$} & t-statistic & -14.309 & -10.884 & -4.225 & -13.687 & -7.582 & -7.382 \\
\hline & Crit. Val. 1\% & -5.34 & -5.34 & -5.34 & -5.34 & -5.34 & -5.34 \\
\hline & Crit. Val. 5\% & -4.80 & -4.80 & -4.80 & -4.80 & -4.80 & -4.80 \\
\hline & Crit. Val. $10 \%$ & -4.58 & -4.58 & -4.58 & -4.58 & -4.58 & -4.58 \\
\hline
\end{tabular}

Note: ADF = Augmented Dickey-Fuller; KPSS = Kwiatkowski-Phillips-Schmidt-Shin; ADF Break = Augmented Dickey-Fuller with structural break; ZA = Zivot-Andrews; and ${ }^{\star}$ Test equation with time trend term. Source: Results of the estimation process. Produced by the authors. 
D. Piper et al.

Table 3. Test of the model: selection criteria, heteroscedasticity test and autocorrelation test.

\begin{tabular}{|c|c|c|c|c|c|c|c|c|}
\hline \multirow{3}{*}{$\begin{array}{c}\text { Level } \\
\begin{array}{c}\text { Selection } \\
\text { criteria }\end{array}\end{array}$} & \multicolumn{2}{|c|}{2} & \multicolumn{2}{|c|}{3} & \multicolumn{2}{|c|}{4} & \multicolumn{2}{|c|}{5} \\
\hline & AIC & SBC & AIC & SBC & AIC & SBC & AIC & SBC \\
\hline & -32.9676 & -30.7415 & -33.0741 & -29.8207 & -32.8624 & -28.5815 & -32.7524 & -27.4441 \\
\hline \multicolumn{9}{|c|}{ Heteroscedasticity Tests } \\
\hline Equation & $x^{2}$ & p-value & $x^{2}$ & p-value & $x^{2}$ & p-value & $x^{2}$ & p-value \\
\hline dptd & 0.0011 & 0.9994 & 1.0672 & 0.7850 & 1.8453 & 0.7642 & 4.1369 & 0.5299 \\
\hline $\mathrm{dcmb}$ & 2.9668 & 0.2269 & 6.7209 & 0.0813 & 5.8060 & 0.2141 & 6.5518 & 0.2562 \\
\hline djur & 1.7245 & 0.4222 & 1.9106 & 0.5912 & 3.3320 & 0.5039 & 3.2123 & 0.6673 \\
\hline duci & 7.0145 & 0.0300 & 3.2696 & 0.3519 & 2.0199 & 0.7321 & 7.3107 & 0.1985 \\
\hline dslr & 0.9826 & 0.6118 & 2.7508 & 0.4317 & 1.2766 & 0.8653 & 2.2182 & 0.8182 \\
\hline dipp & 2.4462 & 0.2943 & 3.7394 & 0.2910 & 1.7999 & 0.7725 & 6.2594 & 0.2818 \\
\hline \multicolumn{9}{|c|}{ Autocorrelation Tests } \\
\hline Lags & $x^{2}$ & p-value & $x^{2}$ & p-value & $x^{2}$ & p-value & $x^{2}$ & p-value \\
\hline 1 & 68.1568 & 0.00096 & 39.7114 & 0.30811 & 40.9333 & 0.26285 & 29.3592 & 0.77540 \\
\hline 2 & 48.8143 & 0.07529 & 42.0495 & 0.22538 & 35.8764 & 0.47444 & 30.3347 & 0.73452 \\
\hline
\end{tabular}

Note: AIC = Akaike Criterion; $\mathrm{SBC}=$ Schwartz Criterion; Heteroscedasticity Test $=$ Portmanteau test for white noise; and Auto-correlation test $=$ Lagrange Multiplier (LM). Source: Results from the estimation process. Produced by the authors.

Table 4. Jarque-Bera test for normality.

\begin{tabular}{cccccccc}
\hline Equation & Dptd & dcmb & djur & duci & dslr & dipp & 0.073 \\
\hline$\chi^{2}$ & 0.224 & 8.689 & 0.637 & 0.714 & 206 & 2 \\
G.L. & 2 & 2 & 2 & 2 & 0.542 & 0.90213 & 0.96430 \\
p-value & 0.89388 & 0.01298 & 0.72713 & 0.6999 & 0.56848 \\
\hline
\end{tabular}

Note: Test with the fourth-order SVAR model. Source: Results from the estimation process. Produced by the authors.

Table 5. Cholesky decomposition.

\begin{tabular}{ccccccc}
\hline Equation & dptd & dcmb & djur & duci & dipp & 0 \\
dptd & 0.0098257 & 0 & 0 & 0 & 0 \\
dcmb & 0.00004992 & 0.03788503 & 0 & 0 & 0 \\
djur & 0.01397239 & -0.00420024 & 0.04657547 & 0 & 0 \\
duci & 0.00143742 & -0.00087231 & 0.00153026 & 0.00420819 & 0.00956542 \\
dslr & -0.00066297 & 0.00224166 & 0.00028373 & 0.00126037 & 0 \\
dipp & 0.00031779 & 0.00283911 & -0.00055389 & 0.00036671 & -0.00031057 \\
\hline
\end{tabular}

Source: Results do estimation process. Produced by the authors.

However, the effects of exchange variation and inflation feedback are rather inelastic, and a $1 \%$ rise in the exchange rate results in an increase of only $0.2 \%$ in PPI, while the analogous coefficient for inflation inertia was $0.3 \%$. The short-term effects on PPI from exchange rate-and feedback by PPI on it- 
self-can be even better understood by examining the graphs for the impulse-response functions associated with the Cholesky decomposition that was performed (Figure 2). Graph (b) reveals that a shock on $d c m b$ is reflected, over time, in cumulative increases in dipp. Graph (f) shows that a shock on dipp produces a rapid response in that variable, which lasts about three periods and then begins to dissipate.

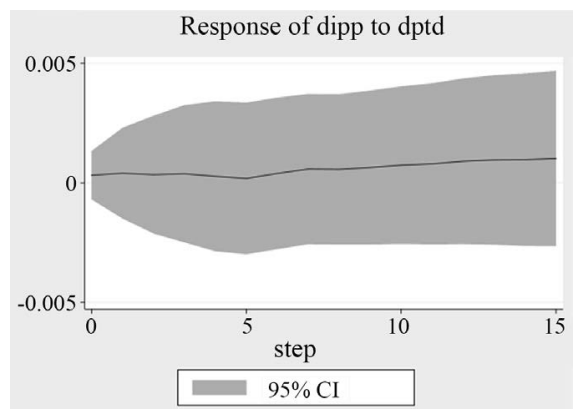

(a)

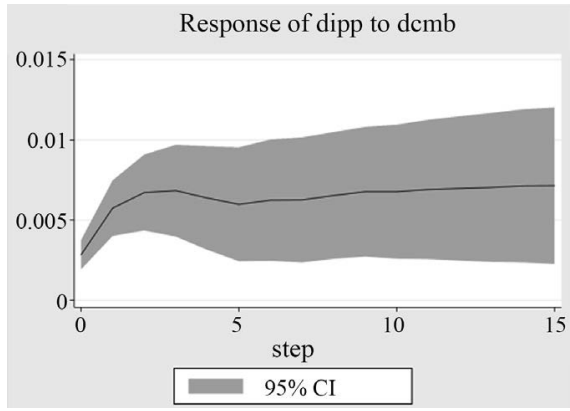

(b)

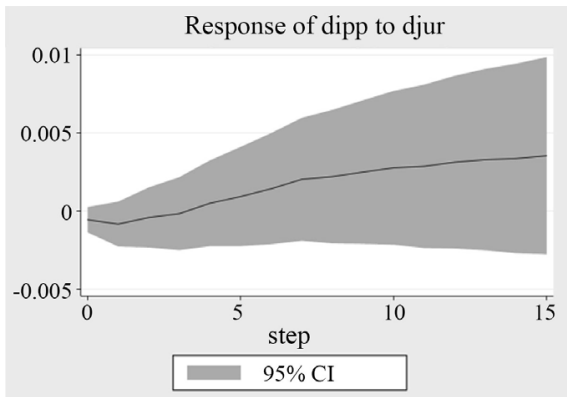

(c)

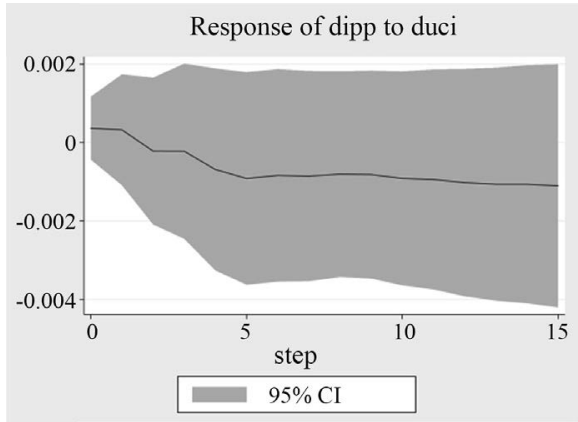

(d) 


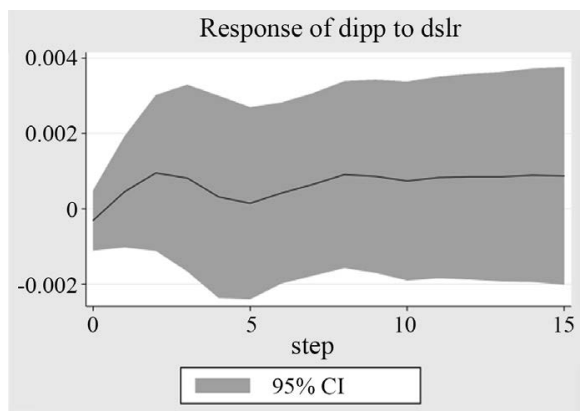

(e)

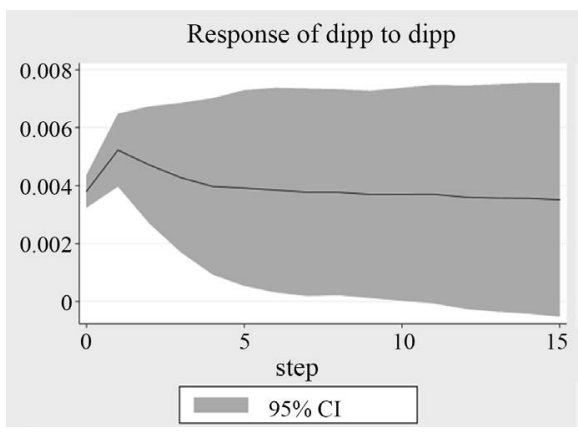

(f)

Figure 2. Impulse-Response Functions (IRFs). Source: Results from the estimation process.

Lastly, Table 6 groups the results from the Blanchard-Quah decompositions with a view to ascertaining what long-term relations are established between the variables involved in the estimation process. Note that exchange variations and the inertial component also stand out, in this method of estimation, as the fundamental determinants of the recent behavior of inflation in the manufacturing industry (this is because they display the highest elasticity coefficients). The evidence obtained shows that a $1 \%$ increase in $d c m b$ led to a $0.5 \%$ expansion in dipp, a coefficient analogous to that for the elasticity of dipp to itself.

Meanwhile, the coefficients estimated for the impacts exerted by wages and utilization of installed capacity did not prove to be statistically significant. In other words, the variable $d s l r$ exerts no significant influence on dipp. This result it is particularly intriguing, given that, in Brazil, nominal wages constitute an important component of firms' costs. Contrariwise, the lack of any substantial correlation between dipp and duci is no cause for surprise, either; rather, it aligns with the idea that inflation in Brazil is not primarily determined by the level of aggregate demand.

The findings regarding the relation between dipp and interest rate proved very telling. It was found that, in the context of the ITR, when SELIC increases, to aim at containing inflationary processes, in the long run, and contradictorily, the inflation rate (dipp) also increases. That effect may be explained by the fact that interest rates influenced firms' financial costs (which were then passed on to final product prices), and it may also be regarded as an indication that using the 
Table 6. Blanchard-Quah decomposition.

\begin{tabular}{|c|c|c|c|c|c|c|}
\hline Equation & Dptd & $\mathrm{dcmb}$ & djur & duci & dslr & dipp \\
\hline \multirow{3}{*}{ dptd } & 0.0106284 & & & & & \\
\hline & $(0.0008057)$ & 0 & 0 & 0 & 0 & 0 \\
\hline & {$[0.000]$} & & & & & \\
\hline \multirow{3}{*}{$\mathrm{dcmb}$} & -0.0203615 & 0.0529174 & & & & \\
\hline & $(0.0058796)$ & $(0.0040117)$ & 0 & 0 & 0 & 0 \\
\hline & {$[0.001]$} & {$[0.000]$} & & & & \\
\hline \multirow{3}{*}{ djur } & -0.0757563 & 0.0046718 & 0.0727121 & & & \\
\hline & $(0.0096956)$ & $(0.0078036)$ & $(0.0055123)$ & 0 & 0 & 0 \\
\hline & {$[0.000]$} & [0.549] & {$[0.000]$} & & & \\
\hline \multirow{3}{*}{ duci } & 0.003604 & -0.0027417 & -0.0029581 & 0.0033499 & & \\
\hline & $(0.000625)$ & $(0.0005223)$ & $(0.0004234)$ & $(0.000254)$ & 0 & 0 \\
\hline & {$[0.000]$} & {$[0.000]$} & {$[0.000]$} & {$[0.000]$} & & \\
\hline \multirow{3}{*}{ dslr } & -0.0038287 & 0.0031609 & -0.0005669 & -0.0007815 & 0.0041907 & \\
\hline & $(0.0006416)$ & $(0.0005196)$ & $(0.0004591)$ & $(0.0004532)$ & $(0.0003177)$ & 0 \\
\hline & {$[0.000]$} & {$[0.000]$} & {$[0.217]$} & [0.085] & {$[0.000]$} & \\
\hline \multirow{3}{*}{ dipp } & -0.003942 & 0.00579 & 0.0033468 & 0.000094 & 0.0009092 & 0.0054324 \\
\hline & $(0.0009758)$ & $(0.0008187)$ & $(0.0006428)$ & $(0.0005906)$ & $(0.0005865)$ & $(0.0004118)$ \\
\hline & {$[0.000]$} & {$[0.000]$} & {$[0.000]$} & {$[0.874]$} & {$[0.121]$} & {$[0.000]$} \\
\hline
\end{tabular}

Note: Standard deviation in round brackets; p-value in square brackets. Source: Results from the estimation process. Produced by the authors.

interest rate as an anti-inflationary instrument-in view of its contractionary impacts on economic activity-proved not only inefficient, but also ineffective.

Lastly, the findings derived by measuring the nature of the link between productivity and inflation in Brazil's manufacturing industry are as follows: the result obtained from the estimates supports the idea presented in the Introduction to this study; that is, the result points to the existence of a statistically significant, inverse relationship between $d p t d$ and dipp. However, the coefficient that has been estimated to reflect the quantity and quality of that relationship shows that it is inelastic, as a $1 \%$ rise in dptd is reflected in a decrease of only $0.3 \%$ in dipp. Accordingly, the proposition that expansions in productivity in the manufacturing industry assist in controlling prices is confirmed, although to a lesser extent than expected.

Finally, if productivity increments in the manufacturing industry are not passed on substantially in the form of price reductions, it is to be concluded that ultimately they must result in expansions in firms' mark-ups. That conjecture may assist in understanding why, in the model estimated, wage increases did not figure prominently as a significant component in determining the dynamics of inflation as measured by dipp. In that connection, as firms operate with a tendency to accumulate profit margins, they can more easily absorb increases in wage costs. 


\section{Conclusion}

The article found, on the one hand, clear indications that, in the recent period-more specifically, from December 2009 to July 2017-PPI for the manufacturing industry showed sensitivity to exchange rate variations and that its dynamic behavior displayed a significant inertial component. On the other hand, PPI was not significantly affected by the degree of utilization of installed capacity, which indicates that the behavior of aggregate demand did not constitute a significantly important determinant in the index's behavior.

In addition, the basic interest rate-the key anti-inflation instrument in the context of the ITR-tended to exert an effect on PPI opposite to the effect desired by the monetary authorities, which confirmed the finding already widely documented in the existing literature: that Brazil's inflation did not respond as expected to monetary contractions. As interest is a component of firms' financial expenditures, that finding stands as yet another indicator of the validity of the post-Keynesian propositions regarding cost inflation (e.g. Araujo, Ferrari Filho, \& Araujo, 2018; Ferrari Filho \& Milan, 2018).

Moreover, when a long-term timeframe is considered, rising interest rate policies under the ITR ultimately undermined the very price stability they were officially designed to preserve, because they subjected the Brazilian economy to an incessant stop-go trajectory. In an emerging economy with inflationary dynamics impregnated by a series of particularities and not determined primarily by aggregate demand conditions-as this study has endeavored to show is the case with Brazil-the phenomenon of inflation should not be regarded as a variable uncorrelated with the national development process. Thus, considering a broader perspective that contemplates cost inflation, it has to be emphasized that supply-side elements are important to explaining inflation in Brazil.

Finally, in structuring the econometric model estimated in this study, the point of departure was given by arguments as to the existence of a relationship between productivity and inflation in the Brazilian economy. The evidence observed did indeed confirm the hypothesis that increments in productivity over time do help to control inflation in the manufacturing industry; however, the magnitude of the effect of expanding productivity proved smaller than expected. In light of that finding, it must be said that productivity gains in Brazil's manufacturing industry are not substantially reflected in price reductions, but as a result are instead significantly absorbed in the form of increases in firms' profit margins. These expansions in mark-up can help to explain why the model estimated indicated that increases in wages paid to workers do not produce significant impacts on PPI, as previously mentioned.

\section{Acknowledgements}

The authors would like to thank two anonymous referees. The authors acknowledge their own responsibility for all remaining errors. 


\section{Conflicts of Interest}

The authors declare no conflicts of interest regarding the publication of this paper.

\section{References}

Aizenman, J., Hutchison, M., \& Noy, I. (2011). Inflation Targeting and Real Exchange Rates in Emerging Markets. World Development, 39, 712-724. https://doi.org/10.1016/j.worlddev.2010.11.005

Araujo, E., \& Arestis, P. (2019). Lessons from the 20 Years of the Brazilian Inflation Targeting Regime. Panoeconomicus, 66, 1-23. https://doi.org/10.2298/PAN1901001A

Araujo, E., Ferrari Filho, F., \& Araujo, E. (2018). Macroeconomic Performance in Brazil under the Inflation Targeting Regime. Investigación Económica, 77, 72-101. https://doi.org/10.22201/fe.01851667p.2018.304.66400

Arestis, P., Ferrari Filho, F., \& Paula, L. F. (2011). Inflation Targeting in Brazil. International Review of Applied Economics, 25, 127-148. https://doi.org/10.1080/02692171.2010.483465

Banco Central do Brasil (BCB) (2019). Séries Temporais. http://www.bcb.gov.br

Blanchard, O. J., \& Quah, D. (1989). The Dynamics Effects of Aggregate Demand and Supply Disturbances. American Economic Review, 79, 655-673.

Braga, J. M. (2011). Inflação no Brasil nos anos 2000: Conflitos, limites e políticas não monetárias. In R. Carneiro, \& M. Matijascic (Eds.), Desafios do Desenvolvimento Brasileiro (pp. 121-136). Brasília: IPEA.

Bueno, R. L. S. (2015). Econometria de Séries Temporais. São Paulo: Cengage Learning.

Câmara, F., \& Feijó, C. A. (2017). Industrial Princing in Brazil in the 2010s: The Pass-Through Effect. Economia, 18, 60-72. https://doi.org/10.1016/j.econ.2016.12.003

Confederação Nacional da Indústria (CNI) (2019). Indicadores Industriais. http://portaldaindustria.com.br

Enders, W. (2015). Applied Econometric Time Series. New York: Wiley.

Ferrari Filho, F., \& Milan, M. (2018). Excess Real Interest Rates and the Inflation Targeting Regime in Brazil: Monetary Policy Ineffectiveness and Rentiers' Interests. Applied Economics and Finance, 5, 84-100. https://doi.org/10.11114/aef.v5i6.3710

Ferrari Filho, F., \& Paula, L. F. R. (2003). The Legacy of the Real Plan and an Alternative Agenda for the Brazilian Economy. Investigación Económica, 62, 57-92.

Fonseca, M. R. P., Peres, S. C., \& Araújo, E. C. (2016). Regime de metas de inflação: Análise comparativa e evidências empíricas para países emergentes selecionados. $R e$ vista de Economia Contemporânea, 20, 113-143.

https://doi.org/10.1590/198055272015

Gentil, D. L., \& Araujo, V. L. (2015). Além da macroeconomia de curto prazo: Notas sobre a debilidade estrutural da economia brasileira no período recente. Revista da Sociedade Brasileira de Economia Política, 41, 54-81.

Instituto Brasileiro de Geografia e Estatística (IBGE) (2019). Informações Estatísticas. http://www.ibge.gov.br

Lütkepohl, H. (2005). New Introduction to Multiple Time Series Analysis. Berlin: Springer. https://doi.org/10.1007/978-3-540-27752-1

Modenesi, A., \& Araujo, E. (2013). Price Stability under Inflation Targeting in Brazil: An Empirical Analysis of the Monetary Policy Transmission Mechanism Based on a VAR 
Model (2000-2008). Investigación Económica, 72, 99-133.

Silva, F. C. M., Feijó, C., \& Modenesi, A. (2018). Dinâmica inflacionária da indústria brasileira: Uma Abordagem abordagem setorial (1999-2014). Brazilian Journal of Political Economy, 38, 690-707. https://doi.org/10.1590/0101-35172018-2863

Sims, C. (1980). Macroeconomics and Reality. Econometrica, 48, 1-48. https://doi.org/10.2307/1912017 